\title{
Tourism Management Professional Training Mode Innovation
}

\author{
Huiyuan Mao \\ Shenyang University, Shenyang 110044, Liaoning, China \\ Tel: 86-24-2389-4862Ｅ-mail: maohuiyuan2004@126.com \\ Zeping Wang \\ Neusoft Corporation, Shenyang 110179, Liaoning, China \\ Tel: 86-24-8661-8365Ｅ-mail: mrwzp@163.com
}

\begin{abstract}
Tourism development puts forward higher requirement to tourism education of colleges and universities. How to adapt to the needs of times, training qualified personnel, construction of new training mode is the key. This paper, aiming at gap phenomenon between tourism professionals of colleges and universities and market demand, analyzes the existing problems in tourism education of colleges and universities and social requirements to the tourism students, puts forward establishing high quality and applied tourism professionals training mode.

Keywords: Tourism Management, Professional, Training Mode

With the rapid development of the economy of China, tourism has become an important economic industry sectors. Frangialli, World Tourism Organization Secretary-General, in Shanghai Expo in 1998, pointed out that: "By 2010, China will become the world's largest tourist receiving country, the fourth largest tourist source country". Meanwhile, the tourism industry also contributed significantly to leap the development of tourism education. Tourism education now has a considerable size, however, the concept of traditional education in tourism, education mode and means phase out of touch with market demand of tourism professionals, showing not adaptation. How to train more and better management professionals for our tourism industry, how to make our existing tourism management education more in tune with actual needs and future tourism development, has become a major issues in front of each educator.
\end{abstract}

\section{On the problems of tourism education}

\subsection{Training targets and competent job dislocation}

Tourism management in China is an emerging profession; it is accompanied by the rapid development of tourism development. The profession in the country is a new profession, which was founded to provide professional development in the larger space, the formation of a different mode. As the late start tourism education, tourism management were mostly teachers, "mid-life switch", thus causing them uncertain about the tourism personnel training objectives, which are not to figure out what type of talent should be cultivated for the tourism industry, so teaching program which, was not aimed at curriculum pertinence, trained students in the knowledge structure, ability to structure and so on, are difficult to adapt to the tourism industry-related positions qualifications.

\subsection{Old concepts of education and teaching methods singleness}

Currently, many tourism management run school behind closed doors, in general professional teaching use the traditional "college-style" teaching methods, the teacher tells, the main students record, classroom lack of energy, depress initiative and creativity of students, neglect methods education and ability cultivation to the students, in some highly practical courses, such as: guided practice, lobby and rooms management, food management, still using traditional classroom teaching methods.

\subsection{Tourism imperfect course design and teaching materials construction lag}

Tourism education is still in start-up and development stage, "set course for families," "teach for teachers," the phenomenon of which is in existence widespread, leading travel professional curriculum to a lack of systematic and integrity. Tourism management teaching materials construction is seemingly prosperous, many colleges and universities publish their own material, but the reality is that many series, are written by less than edited, the theory more than operation, inherited more than innovative, since the building of tourism materials in China or tourism discipline structure is taking a "top down" route, the path often leads to the development of this reverse 
the "quick" mentality, resulting in the construction materials only "used", no "self-idea", the contents of old, repetitive and more.

\subsection{Weak links of teaching practice}

Practice teaching is the basic approach of vocational education quality assurance, is the basic measurement to implement the students professional ability cultivation. However, presently a common problem in colleges and universities is the shortage of the funding of construction in the training base, which has seriously affected the commencement of training courses. Meanwhile, the tourism business in general worry about the arrangements for school students practice will affect the service quality and corporate reputation, so do not hold a very welcome attitude for the students to practice. Some of the students to practice in tourism enterprises are to serve as teaching practice in the labor force, not for changing of the guard practice and management practice. Because of the shortage of reliable practice base, students lack the opportunity to practice, so hands ability can not be trained and exercised very well.

\subsection{Neglect of professional ethics and culture of non-intellectual factors}

Having good professional ethics for the tourism staff, is one of the basic quality. At present commonly colleges and universities is in existence focusing on professional knowledge of learning, making light of moral, emotional intelligence training and other non-intellectual factors of education. Therefore, tourism management institutions should put cultivating good professional ethics on the importance of school education teaching position, while paying attention to mutual communication and infiltration of intelligence and emotional quotient of education. Intellectual factors of students are in the development, while developing the interest, emotion, personality and other non-intellectual factors of students.

\subsection{The overall strength of the faculty of tourism not strong}

Tourism management in our existing team of professional teachers, some are diverted from other professions, did not receive systematic professional study tour, this part of the professional quality of teachers still need to be improved. In addition, the training of tourism teachers and continuing education have not yet implemented a comprehensive and systematic management of tourism on promoting the quality of professional teachers, tourism practice without tempering, the ability to combine theory and practice is less than echo what the books say. Even if having received a professional training for what one is doing, however, because of the lack of practice opportunities, it also affects the consolidation and improvement of their quality. As the knowledge structure of professional teachers and the quality of their many inadequacies exist, leading more constraints to cultivating and improving of the ability of applying of students.

\section{Having the quality of tourism students}

\subsection{Reasonable knowledge structure}

Knowledge is the basis of talent training, to meet the requirements of professional ability, knowledge structure of tourism students should reflect the level of basic knowledge, expertise and related knowledge, the unity of theoretical knowledge and practical training, the correspondence of the knowledge content and the job requirements. Tourism practitioners need to have culture, basic knowledge, professional knowledge, the knowledge of professional theory and the practice application for the positions demand, the development knowledge of cultivating adaptation to community and innovative ability.

\subsection{Certain professional expertise}

Tourism profession is a strong professional practice, practitioners need to have strong knowledge in addition to the structure, should also have strong practical ability, observation ability, professional key capacity and skilled specialized capabilities. So that they can be more into the role quickly after coming into companies to assume their responsibilities, reduce post application stage, and become useful business professionals through business training.

\subsection{Good ethics and professionalism}

Quality education includes a wide range, including the moral, psychological and professional qualities of the students. Schools are in strengthening the moral, mental quality education, while strengthening the training of professional quality of the students is particularly important, professional quality should be the qualities which are possessed by the practitioners to adapt the requirements of professional positions, generally including professional quality and the social quality of meeting the social development and position transformation. Loving the tourism industry, having sufficient confidence and patience, are rooted in their own careers, and strive to become excellent students of tourism. 


\section{Creative Tourism Training Mode}

\subsection{Clear educational direction and training objectives}

At present there are three modes for the world of higher education: The first one is research mode, the second one is applied mode, and the third one is between the two above. Tourism education notable feature is applied very strong, the overall objective is to develop practical talents, but is different at different levels, undergraduate institutions and above are to train middle and senior management personnel, or white-collared and even the golden-collar professionals; vocational colleges are to train primary and middle management personnel, or grey-collar talents; secondary school is to train skilled service personnel, or blue-collar professionals. Tourism management training objectives can be defined as: training with good overall quality, proficiency in the tourism industry needs of all the professional theory and application of theory of every occupational status, with comprehensively vocational and technical capacity, to meet the 21 st century tourism management needs of high-level and applied talent.

\subsection{Changing the traditional teaching system, implementing the modernization of teaching methods and teaching} means

Tourism education should be stable, rapid and healthy development, we must break through the traditional teaching mode, break through the mode of teacher-centered, textbook-centered, teaching-centered, abolish the ideological injection of the chalk and talk, turn to highlight the student- status, cultivate learning ability and sense of innovation of the students, and enhance the education of learning methods and capacity training of the students, to update the content of education and highlight the times by the tourism market dynamic. Teaching methods and teaching means in the concrete implementation, transmitted from a single classroom to a variety of teaching methods, such as case teaching, video teaching, simulated teaching and practice teaching etc, which are not only to do a variety of teaching methods complement each other, but also pragmatic, meanwhile, take full advantage of modern teaching methods, take an active part in theory and technology research of modern management tools and academic exchange activities, learn advanced level, enrich teaching content and improve the effectiveness of teaching.

\subsection{Optimizing the course structure and establish the "general education" courses system}

Training course structure is the core to carry out the training goal and to improve the quality of personnel training. Tourism management curriculum should reflect the intellectual capacity of modern education and the curriculum trinity of teaching, research and practice. Tourism education as the basis protection for tourism development, it is not a pure closed-style education college, which has its own strong industry characteristics and clear objectives; tourism education is the unity of basic education and practice of education. Therefore, the tourism curriculum system which is designed according to the goals of tourism education and training and personnel specifications, seeks the most direct inner contact of professional internal knowledge and skills structure, designs various practical "combination course", streamlines the integration of professional courses, strengthens the foundation courses, increases elective courses, promotes to rationalize the structure of professional knowledge and basic knowledge, theoretical knowledge and practical knowledge, ensures the best mix of knowledge. To enhance the practice teaching of the depth and breadth forms a course structure based on a professional curriculum and backed by integrated curriculum and the edge of cross-curriculum.

\subsection{Adhere to moral first, importance of non-intellectual factors in culture}

Tourism professional personnel training has proven that, the role of tourism human resources in the social development are not just superb engineering skills and the operational capacity of skilled, the training missions of ideological and moral aspects of students are more important. The value of moral education is to enable students to understand how to be a man. Moral education of tourism colleges must adhere to a unified direction, establish a correct outlook on life's guide, and highlight the main theme of patriotism in education. Tourism management training goal is more to achieve from four levels of the knowledge, training, ability and physique, none is dispensable. Tourism management education takes into the mutual communication and infiltration of IQ education and EQ education, from the emphasis on intellectual factors training, turning into the development of intellectual factors of students, in the same time, pays attention to the development of non-intellectual factors of students in interest, emotion and personality etc.

\subsection{Strengthening the teaching practice and training applied talents}

Actual tourism in our country, the students practice in the tourism business for at least six months or so. In order to improve the practice abilities of students and cultivate high-quality application personnel, addressing the requirements of operation skill of employees in tourism enterprises, should establish a emulated simulation 
training laboratory in schools, such as catering training room, room training room, analog front hall, analog bar, guide simulation training room, equipped with the appropriate training equipment, in order to achieve the operation training which could not be completed in class. In addition, tourism institutions and departments of the tourism industry must establish long-term alliances, especially alliances between schools and enterprises, which is the best choice for integration of the practice and the employment. This is not only to solve the gap issues between theory and practice, but also to make up the shortage of teaching facilities and establish relatively stable practice base through cooperation with enterprises and the use of existing business resources and conditions.

\subsection{Taking the road of integration of "production, academic and research"}

Tourism education must focus on the hands abilities of students, strengthening the practice lesson. Practice teaching is an integral part to train outstanding travel professionals. By combining production and academic, it can coordinate the relationship between the development needs of the tourism industry and tourism college training. Schools and tourism enterprises to establish long-term relationships and an education and employment base, it does not only provide students with the practice of a large number of post opportunities, but also the overall quality training required by practical work. Through the combination of production and research, it can coordinate the relationship between the development of tourism demand and higher travel academic research. Through the combination of academic and research, it can coordinate the relationship between teaching and research. By the conduct of research activities, it does continuously improve the analytical skills and problem-solving abilities, continuously enrich the content of teaching and improve teaching level. Tourism colleges for tourism only take the road of integration of "production, academic and research", can the cultivation of tourism professionals link with the demand for travel market, promote tourism, rapid, coordinated and sustainable development.

\section{References}

Liu, Fen \& Sheng, Zhengfa. (2008). The analysis of trinity tourism management training mode. Hunan Commercial College Journal, (3), 53-55.

Qu, Na, Wang, Duchun \& Liu, Yong. (2009). Thinking and innovation of tourism management professional training mode in colleges and universities. Business Economy, (11), 117-118.

Wang, Qingrong. (2006). First exploration of tourism management training model of experience in teaching. Tourism Science, (4), 89-92. 